\title{
Ivan Hlaváček
}

\section{Zur böhmischen Inquisition und Häresiebekämpfung um das Jahr 1400}

Obwohl im Kreise der Symposiumsteilnehmer sicher mehrere von den hier Anwesenden kompetenter als der Verfasser dieses Beitrages wären, das angezeigte Thema zu behandeln, fiel dieser an sich mir angenehme "Schwarze Peter" - ich werde sofort erklären warum - an mich. Mir scheint nämlich, daß in einer thematisch so ausgerichteten Tagung das Thema der Inquisition nicht unberücksichtigt bleiben darf, ja es sollten ihm eigentlich mehrere Referate gewidmet werden. Doch dürfte es auf jeden Fall besser sein, in nur einem Beitrag sich dieser Frage anzunehmen, als diese Problematik völlig außer acht zu lassen. Um den „Schwarzen Peter" handelt es sich jedoch nur in gewisser Hinsicht, da ich - freilich eher zufälligerweise - doch imstande bin, etwas Neues zum bisher Bekannten beizusteuern ${ }^{1}$.

Jedoch muß man zuerst den Versuch wagen, unser Vorhaben in einen zumindest ein wenig breiteren Zusammenhang einzureihen. Die Sache kann nämlich in diesem, d.h. bohemikalen Kontext, in einem guten Teil, vielleicht sogar vornehmlich und nicht nur rein historisch oder sozial- und kirchengeschichtlich, sondern überraschenderweise in erster Linie überlieferungsgeschichtlich als modellartig bezeichnet werden. Wie darf man dies verstehen? Die die Inquisition ${ }^{2}$ allgemein

${ }^{1}$ Das Thema habe ich bislang zwar zweimal, jedoch sehr knapp und in schwer zugänglicher Literatur, gestreift: Zum ersten Male geschah dies unter dem Titel „ $Z$ dosud neznámých pramenů doby předhusitské "im Jahre 1983, als die maschinenschriftliche Hommage zum 60. Geburtstag von Amedeo Molnár (1923-1990) vorbereitet wurde, die jedoch lediglich in einem einzigen maschinenschriftlichen Exemplar dem Jubilar überreicht werden konnte. Zum anderen habe ich dann in einer noch kürzeren Fassung als "Colligere fragmenta. $\mathrm{K}$ dosud neznámým diplomatickým pramenům doby lucemburské", in: Sborník kruhu přátel Muzea hl. města Prahy 1 (1988) 129-135, hier 130 f., auf diese Problematik verwiesen.

2 Ohne die umfangreiche Literatur wiedergeben zu wollen und zu können, sei nur bemerkt, daß im Lexikon des Mittelalters weder das Stichwort "Inquisition“ noch „Inquisitionsprotokoll" vorkommt, sondern lediglich "Inquisitionsprozeß“ (Bd.5, Sp. $441 \mathrm{f}$.), ja auch innerhalb der Planung in der Typologie der Sources du moyen âge occidental findet man überraschenderweise keine Quellengattung, die mit der Inquisition zusammenhängen könnte. Deshalb sei neben den unten zitierten Arbeiten von Alexander Patschovsky, Herbert Grundmann (vornehmlich seine „Ketzerverhöre des Spätmittelalters als quellenkritisches Problem“, in: DA 21 [1965] 519-575 sowie der Nachdruck in: ders., Ausgewählte Aufsätze 1 [= Schriften 
betreffenden Quellen, die kurz vorgestellt werden müssen, weisen - grob betrachtet - einen dreifachen Charakter auf. Es handelt sich dabei nämlich 1) um Informationen der chronikalischen Überlieferung aller Gattungen des historiographischen Quellenguts;

2) um Quellen von allgemeinem, d.h. vornehmlich normativem Charakter, wozu jedoch nicht nur, ja nicht einmal in dominierender Weise, die Urkunden zu rechnen sind, sondern auch verschiedene Rechtsbücher, wie die nachfolgend noch näher zu erörternde Maiestas Carolina und mit gewisser Zurückhaltung auch die inquisitorischen Handbücher, wobei jedoch das in ihnen konkret angeführte Material natürlich die Einzelgattungen sprengt und mindestens auch in die letzte Gruppe eingereiht werden könnte;

3) um die eigenen konkreten Produkte der „amtierenden“ Inquisition an Ort und Stelle, die erst den direkten Einblick in den Alltag der Inquisition, d.h. auch in ihren ganz speziellen Umfang und Verlauf gewähren. Diese lassen sich ansonsten aus anderen Unterlagen kaum entsprechend bzw. überhaupt nicht rekonstruieren, wenngleich eben gerade diese Fragen von ganz entscheidender Wichtigkeit sind, $\mathrm{da}$ erst durch sie etwas über die konkrete Bedeutung der diesbezüglichen Aktionen innerhalb der Regional- bzw. Landesgeschichte und vornehmlich über ihre Ausmaße in Erfahrung gebracht werden kann.

Absichtlich habe ich die Reihenfolge der Einzelgattungen, wie eben dargelegt, an den Beginn gestellt. Meiner Ansicht nach läßt sich hieraus ziemlich überzeugend eine gewisse Graduierung innerhalb der spezifischen Bedeutung einzelner Quellengattungen ablesen, da es als selbstverständlich gelten muß, daß für den eigenen konkreten historischen Verlauf der Dinge das Material der Inquisitionsprotokolle am ergiebigsten ist, ja sein muß.

Wenn man jedoch die Quantität bzw. konkreter die relative Menge der Hauptgattungen untereinander vergleicht, sieht man bald, daß hier mehrere tiefgreifende Disproportionen zum Vorschein kommen. Mit anderen Worten heißt das, daß die erste (historiographische) Gruppe am integralsten - natürlich sit venia verbo - erhalten geblieben ist, obwohl sie eigentlich in puncto Konkretheit im Grunde genommen kaum etwas zu bieten vermag. Mehr verspricht diesbezüglich die zweite Gruppe, ganz gleich ob es sich nun um die unterschiedlichsten päpstlichen Bullen, die konkreten Urkunden lokaler Machthaber oder die bloßen Nennungen der eigenständig wirkenden Inquisitoren in anderen, allgemeineren Zusammenhängen handelt, die im entsprechenden Kontext mit den inquisitorischen Handbüchern zwar in die allgemeinen prozessualen Zusammenhänge Einsicht gewähren und die Inquisitoren sozialgeschichtlich einreihen, die jedoch nicht das wirklich

der MGH 25-1], [Stuttgart 1976] 364-416) und Hermann Heimpel, dessen Beiträge jedoch bereits die eigentliche Zeit der hussitischen Revolution zum Inhalt haben und dem Reichsterritorium gewidmet sind (vgl. František Šmahel, Husitská revoluce 4 [Praha 1994] 259, dessen Werk jedoch auch darüber hinaus mit Nutzen für die allgemeinen historischen "Hintergründe" und Zusammenhänge heranzuziehen ist), nur der ein wenig "beckmesserische“ Matthias Benad, Domus und Religion in Montaillou (Tübingen 1990) und seine Bibliographie (S. 362 ff.) angeführt, wo allerdings aus unserer Sicht manches fehlt. 
Reale, Geschehene widerzuspiegeln im Stande sind. Aus diesem Grunde vermögen diese Quellen nicht den realen Tatbestand entsprechend zu quantifizieren, von der Qualität ganz zu schweigen. Dies kann eigentlich nur bei den spezifischen Inquisitionsprotokollen der Fall sein, die jedoch sehr spärlich auftauchen bzw. sehr selten erhalten geblieben sind, wenngleich sie zweifelsohne sehr zahlreich angelegt wurden. Die Protokolle des Bischofs von Pamiers, Jacques Fournier, des späteren Papstes Benedikt XII., für Montaillou müssen hier als Ausnahmefall betrachtet werden, der andererseits aber gleichzeitig wiederum die Regel bestätigt.

Doch kehren wir zum Thema der mittelalterlichen Inquisition in Böhmen zurück, die die gesamte Geschichte Böhmens bzw. der Böhmischen Krone im Spätmittelalter sehr nachhaltig beeinflußte, auf der anderen Seite jedoch in der Historiographie bis zu den Arbeiten Alexander Patschovskys keine entsprechende Würdigung fand, ja nicht finden konnte. Mit anderen Worten bedeutet dies: Alles, was in diesem Kontext Erwähnung finden muß, läßt sich - nach Ansätzen bei Rudolf Holinka ${ }^{3}$ - in A. Patschovskys weithin bekannten und nie genug zu lobenden Arbeiten nachlesen, die zudem die Nachrichtengattungen aus zweiter Hand sorgfältig verzeichnen ${ }^{4}$. In diesem Zusammenhang ist zu sagen, daß die ältesten Erwähnungen der Häresie und ihrer Bekämpfung in Böhmen relativ weit in das 13. Jahrhundert zurückreichen. Es handelt sich dabei allerdings ausschließlich um pauschale Hinweise, denen nicht zu entnehmen ist, was sich wirklich ereignete.

${ }^{3}$ Sektár̆ství v Čechách před husitskou revolucí, in: Sborník filosofické fakulty University Komenského v Bratislavě, Jg. 6, Nr. 52 (1929) 125-312 (auch separate Paginierung).

${ }^{4}$ Es handelt sich vornehmlich um Die Anfänge einer ständigen Inquisition in Böhmen. Ein Prager Inquisitoren-Handbuch aus der ersten Hälfte des 14. Jahrhunderts (Berlin, New York 1975) (=Beiträge zur Geschichte und Quellenkunde des Mittelalters, Bd.3) und Quellen zur böhmischen Inquisition im 14. Jahrhundert (Weimar 1979) (=Monumenta Germaniae Historica-Quellen zur Geistesgeschichte des Mittelalters, Bd.11). Von den zahlreichen häresiologischen Arbeiten Patschouskys seien hier nur diejenigen erwähnt, die Böhmen im 14. Jahrhundert unmittelbar betreffen. Dies sind: Waldenserverfolgung in Schweidnitz 1315, in: DA 36 (1980) 137-176; Ketzer und Ketzerverfolgung in Böhmen im Jahrhundert vor Hus, in: Geschichte in Wissenschaft und Unterricht 32 (1981) 261-272; Was sind Ketzer?, in: „... eine finstere und fast unglaubliche Geschichte"? Mediävistische Notizen zu Umberto Ecos Mönchsroman „Der Name der Rose“, hrsg. von M. Kerner (Darmstadt 31988) 169-190; Wie wird man Ketzer?, in: Volksreligion im hohen und späten Mittelalter, hrsg. von Peter Dinzelbacher und Dieter R. Bauer (Paderborn, München, Wien, Zürich) (Quellen und Forschungen aus dem Gebiet der Geschichte, H. 13) (1990) 145-162; Gli eretici davanti al tribunale. A proposito dei processi-verbali inquisitoriali in Germania e in Boemia nel XIV secolo, in: La parola all'accusato, hrsg. von Jean-Claude Maire Vigueur und Agostino Paravicini Bagliani (Palermo 1991) 242-267; Spuren böhmischer Ketzerverfolgung in Schlesien am Ende des 14. Jahrhunderts, in: Historia docet (Praha 1992) 357-387; über die politische Bedeutung von Häresie und Häresieverfolgung im mittelalterlichen Böhmen, in: Die Anfänge der Inquisition im Mittelalter, hrsg. von Peter Segl (Köln, Weimar, Wien 1993) 235-251. Im Kontext mit Patschovskys Quellen ist zugleich auf František Šmabels Aufsatz in Husitský Tábor 3 (1980) $139 \mathrm{f}$. hinzuweisen, wo mir allerdings die Schlußfolgerung des Autors, die zurückhaltende bis ablehnende Stellung der deutschen Minderheit in Böhmen gegenüber der (tschechischen) Reformbewegung resultiere aus der Erschöpfung der deutschsprachigen Bevölkerung infolge der eben vornehmlich gegen sie geführten Inquisition, nicht überzeugend genug scheint. 
Dasselbe galt lange Zeit auch für das 14. Jahrhundert, bis Ferdinand Menčík und Adalbert Fuchs das sog. Göttweiger Inquisitionsfragment aus der Spätzeit der Regierung Johanns von Luxemburg nahezu zeitgleich edierten. Dieses Dokument stellte über Jahrzehnte den einzigen schlagenden Beweis für die in (Süd-)Böhmen wütende Inquisition dar, deren Existenz zwar verschiedene Deperdita zu avisieren vermochten, ohne daß es gelungen wäre, hier eine konkrete Einschätzung zu tref$\mathrm{fen}^{5}$. Nur die zuständigen, ziemlich ausführlichen Passagen in der Maiestas Carolina Karls IV., dem bekanntlich aus formellen Gründen nicht ins Leben gerufenen Landrechtsbuch des Königreiches Böhmen aus der Mitte der fünfziger Jahre des 14. Jahrhunderts 6 , deuteten die fortlaufende Kontinuität des Ketzereiproblems in Böhmen an. Diese war bislang für die Zeit bis zum Auftreten des Hussitismus lediglich und nur andeutungsweise auf das Jahr 1393 bezogen für die nordwestböhmische Landschaft durch den später noch zu besprechenden, jedoch bezeichnenden Fund Truhlárs vor rund einhundert Jahren, konkretisiert worden.

Erst der Spürsinn und zugleich die unermüdliche Sammelarbeit A. Patschovskys haben deutlich, ja bedrückend, das ungeheure Ausmaß der Inquisition in Böhmen in der Zeit Karls IV. aufgezeigt ${ }^{7}$, die mehrere Regionen des Landes, insbesondere im Süden Böhmens, geradezu verheerend heimsuchte. Bereits diese Belege allein sind imstande, reichlich darzulegen, daß die böhmische Inquisition eine weit verbreitete und permanent arbeitende Institution war, die durch ihre tiefgreifende und systematische Arbeit das Land in mehrerlei Hinsicht zu ruinieren vermochte, da die Inquisition durch ihre Tätigkeit nicht einzelne Personen, sondern hunderte, ja vermutlich tausende offensichtlicher, aber auch heimlicher Ketzer aufspürte. Dabei zog sie einige Regionen des Landes besonders in Mitleidenschaft. Daß damals vornehmlich die deutsche Bevölkerung in Stadt und Land zu leiden hatte, sei an dieser Stelle nur am Rande erwähnt.

F. M. Bartoš, der Altmeister nicht allein der tschechischen Hussitismusforschung (1889-1972) nach dem Zweiten Weltkrieg, hat es - ohne natürlich die Funde Patschovskys aus der Zeit Karls IV. vorwegnehmen zu können - wiederholt bedauert, daß die ihm zur Verfügung stehenden, spröden Belege nicht (freilich mit Ausnahme des schon erwähnten, winzigen Bruchstücks von Truhláŕr), unmittelbar in die vorhussitische Zeit reichten, so daß es aus seiner Sicht methodisch nicht zulässig war, die inquisitorischen Aktivitäten der Zeit Karls mit dem Aufkommen und der Entfaltung des Hussitismus in direkten Zusammenhang zu bringen. Dazu sei bemerkt, daß es methodisch kaum angebracht schiene, dies auch unter der Voraussetzung zu tun, daß es derartige Belege gäbe, da die diesbezügli-

${ }^{5} \mathrm{Da}$ alles bisher bekannte in Patschovskys in Anm. 4 zitierten Arbeiten, vornehmlich dann in seinen Quellen, ausführlich genug aufgeschlüsselt ist, brauche ich dies hier nicht näher zu dokumentieren.

6 Seit kurzem ist die neue kritische Edition von Bernd-Ulrich Hergemöller, Maiestas Carolina. Der Kodifikationsentwurf Karls IV. für das Königreich Böhmen von 1355 (Veröffentlichungen des Collegium Carolinum 74, München 1995) $24 \mathrm{ff}$. zur Hand zu nehmen.

7 Vgl. Anm. 4.

8 Vgl. unten Anm. 20. 
chen Aktionen auf unterschiedlichen, zum guten Teil nichtkompatiblen Ebenen verliefen, die sich nämlich kaum tangierten, geschweige denn durchdrangen. Die Entdeckung neuer Funde macht es notwendig, das so gewonnene Bild mehrdimensional zu betrachten. Mit anderen Worten bedeutet dies, daß der Schauplatz zumindest eine Dimension mehr besaß, als wir bislang annehmen durften. Doch nun zum konkreten Sachverhalt.

Die berühmte altehrwürdige Bibliothek des Prämonstratenserstiftes Strahov (Mons Sion) in Prag verwahrt in ihrer Fragmentensammlung zwei lose Papierblätter, die schon vor Jahren der bedeutende tschechische Mittellatinist Bohumil Ryba (1900-1980) im Zuge der Katalogisierung des entsprechenden Bestands beschrieben hat. Er wußte natürlich ihre Bedeutung einzuschätzen, doch lag es ihm als Philologen fern, dieses Material zu bearbeiten, ja, er hielt es nicht einmal für sinnvoll, gerade die Historiker darauf aufmerksam zu machen, so daß die Quelle zunächst unbearbeitet blieb, bis es schließlich vor Jahren der Kollege Miroslav Truc war, der mich liebenswürdigerweise auf diese Bruchstücke hinwies, die bis dahin nur sehr knapp und versteckt bekanntgemacht worden waren, ohne daß sie ein Echo ausgelöst hätten. Daher soll an dieser Stelle ein ausführlicherer Versuch unternommen werden, diese vorzustellen. Zuvor ist jedoch noch eine typologisierende Vorbemerkung notwendig, die bereits - bei aller denkbaren Kürze - der Sehnsucht Bartoš' gerecht zu werden scheint. Es handelt sich um die Arten der Inquisitionsprotokolle im allgemeinen. Ohne allzu viel zu theoretisieren, glaube ich, die Protokolle mit häretischen Ansichten bzw. Lehren wenigstens im böhmischen Kontext in zwei Kategorien unterteilen zu können, ohne dabei zugleich die technische, d.h. die diplomatische Seite der Dinge berücksichtigen zu müssen. Die erste, weit verbreitetere Kategorie bilden, wie es scheint, die allgemeinen Inquisitionsprotokolle, die sozusagen Ausdruck der durchgehenden oder wenigstens fast durchgehenden, „flächendeckenden“ Inquisitionsarbeit darstellen, in denen alles "ungeordnet" verzeichnet wurde und zwar im Rahmen einer systematischen Tätigkeit „im Feld“, freilich meist am Hauptsitz des jeweiligen Inquisitors.

Die zweite Gruppe bilden dann die genau zweckgebundenen Inquisitionsprotokolle, die aufgrund des ganz speziellen Auftrags an den Inquisitor durch ihn für konkrete causae angelegt wurden. Und für beide Gattungen kann ich im folgenden je einen im wesentlichen unbekannten Beleg vorstellen'. Diese Feststellung muß jedoch sofort in dem Sinne eingeschränkt werden, daß es sich in beiden Fällen nur um zwei kleine, d.h. nur um Ein-Folio-Bruchstücke handelt, die allerdings - und dies halte ich für besonders wichtig - das inhaltlich, räumlich und zeitlich Entscheidende verraten. Zuerst aber noch ein paar Worte über ein Phänomen, das mich bei fast allen Fragen, die ich an die mittelalterliche Geschichte stelle, verfolgt. Es handelt sich um die Deperdita-Frage, die besonders dort von Bedeutung ist,

9 Im folgenden bezeichne ich die Fragmente als A und B. Die illustrative Abbildung der Vorderseite des Fragments B habe ich den Autoren eines ketzergeschichtlichen Werkes zur Verfügung gestellt: Miroslav Hroch, Anna Skýbová, Ecclesia militans. Inquisition im Zeitalter der Gegenreformation (Leipzig 1985) 45. An der Formulierung der entsprechenden Legende habe ich mich jedoch im Endstadium nicht beteiligt. 
wo es um Quellen geht, deren Autoren keine kontinuierlich-institutionellen Fortsetzer fanden, und die mitunter fast oder überhaupt spurlos verschwanden. $\mathrm{Zu}$ dieser Frage kehre ich noch einmal am Schluß meiner knappen Ausführungen zurück, deshalb jetzt zunächst zur Vorstellung „unserer Quellenfunde“.

Beide uns interessierenden Fragmente, also sowohl A als auch B (beide tragen in Strahov die gleiche Inv.-Nr. 657/zl), waren im Einband einer Inkunabel verborgen, die im Jahre 1650 als Eigentum des Zisterzienserstiftes Königsaal südlich von Prag belegt ist ${ }^{10}$. Daß der Kodex wohl gleich nach der Aufhebung des Klosters durch Joseph II. nach Strahov gelangte, versteht sich fast von selbst ${ }^{11}$, interessanter wäre jedoch zu wissen, wie es um seine vorherigen Geschicke bestellt war. Diese lassen sich leider nicht genauer (im Grunde genommen überhaupt nicht) ermitteln, da keine sicheren diesbezüglichen Anhaltspunkte in den Quellen nachweisbar sind. So darf lediglich vermutet werden, daß dieser Wiegendruck nach Königsaal schon bald nach der Wiederherstellung des Klosters nach den Hussitenkriegen (die erste Verwüstung erfolgte zu Beginn der hussitischen Revolution $^{12}$ ) gekommen ist und dort irgendwie auch die Katastrophe des Jahres 1639, d.h. die Inbrandsetzung des Monasteriums durch die Schweden unter Banér, überstand. Sollte dem in der Tat so gewesen sein, dürfen wir voraussetzen, daß irgendwann kurz nach den Hussitenkriegen in Königsaal eine Person Zuflucht fand, die zumindest enge Kontakte zur böhmischen vorhussitischen Inquisition besaß bzw. dieser direkt angehörte. Diese Vermutung läßt sich momentan noch nicht weiter konkretisieren, doch kommt ihr im übrigen nur eine geringe Bedeutung zu. Interessant kann eigentlich nur sein, daß man in der künftigen Bearbeitung des verstreuten buchgeschichtlichen Materials der Aularegiaensia darauf achten sollte, ob dort nicht zufällig weitere Fragmente auftauchen ${ }^{13}$.

10 Konkret handelt es sich um die Goldin Bibel des Antonius Rampigolis, sig. DM IV 30 (vgl. Ludovicus Hain, Repertorium bibliographicum in quo libri omnes ab arte typographica inventa usque ad annum MD expressi ... enumerantur vel ... recensentur, [Stuttgart 1838] II-2, Nr.13690 [auch Nachdruck] und Isidor Zahradnik, Prvotisky knihovny strahovské, in: Věstník České akademie věd a umění 11 [1902] 597-635, hier 618 und 630, der jedoch wegen der äußersten Knappheit für unsere $Z$ wecke nichts bietet).

11 Auf fol. $1^{\mathrm{r}}$ heißt es: Monasterii Aulae Regiae 1650. Zu den Schicksalen der Königsaaler Bibliothek nur soviel, daß die meisten Handschriften auf Irrwegen in alle Winde zerstreut wurden (vgl. besonders knapp bei Ferdinand Tadra, Listy kláštera zbraslavského [Praha 1904], Einleitung und der dort zitierte Aufsatz von Maximilian Millauer). Ein ähnliches Schicksal traf auch die gedruckten Bücherschätze (die Inkunabeln sind z.B. nicht nur in Strahov [vgl. Zabradnik, Prvotisky, wie vorherige Anm. S. 630, der über neun Stücke Bescheid weiß], sondern auch in Kaschau, vgl. Imrich Kotvan, Inkunábuly na Slovensku [Martin 1979] 108), was Einzelheiten auch anderswo vermuten läßt.

12 Vgl. Václav Vladivoj Tomek, Dějepis města Prahy 42 (Praha 1899) 93 und zur allmählichen Wiederherstellung nach der hussitischen Revolution Rudolf Urbánek, České dējiny III-1 (Praha 1915) 151.

13 Daneben überrascht, warum dieser Kodex nicht in die damalige Universitätsbibliothek zu Prag (heute Nationalbibliothek) kam, wohin eigentlich alle schriftlichen Schätze der aufgelösten Klöster gelangen sollten. Dies verwundert um so mehr, als das urkundliche Klosterarchiv dort wirklich ziemlich unversehrt Zuflucht fand. Eigentlich unterstreicht auch dies die 
$\mathrm{Da}$ es sich bei der Inquisition nicht um Belege der ordentlichen Zentralverwaltung der böhmischen Kirche handelte, ist vorauszusetzen, daß die Bände, deren Fragmente wir jetzt kennen, mit Hilfe einer uns unbekannten Person aus dem Kreis der Inquisitoren nach Königsaal gelangten oder doch durch eine Person, die mit diesem Umfeld in Verbindung stand. Es mag nur wenig überraschen, daß die Unterlagen der Inquisition, die nicht nur allgemein, sondern eben auch direkt in Böhmen zumeist in den Händen des Predigerordens (oder besser der Angehörigen des Predigerordens) lagen ${ }^{14}$, in einem Zisterzienserkonvent auftauchen. In Böhmen in der vorhussitischen, v.a. jedoch der hussitischen und begreiflicherweise auch der nachhussitischen Zeit waren jedoch die Verhältnisse derart turbulent, daß solch verschlungene Wege als normal bezeichnet werden können ${ }^{15}$.

Nun wollen wir jedoch die späteren Geschichten und Geschicke der uns interessierenden Bruchstücke beiseite lassen, auch soll von eventuell weiteren, vornehmlich überlieferungsgeschichtlichen Fragen Abstand genommen werden. Nachfolgend interessieren uns nur die konkreten Relikte sowie deren Inhalt und Charakter. Die beiden Papierfragmente weisen Ausmaße von 26,8-27,4 cm x 18,2$19,5 \mathrm{~cm}$ auf und sind von zwei, typologisch verwandten Schreibern, die die gängige gotische Kursive der Zeit um 1400 benutzten, geschrieben. Inwieweit die Marginalien von anderen Händen herrühren, ist wegen des anderen Charakters der Schrift nicht zu ermitteln. Deren Nähe ist folglich nur durch die gleiche Zeit und das gleiche Milieu gegeben und muß so gedeutet werden, als handle es sich um völlig unabhängige Schreiberhände. Auf den ersten Blick könnte man meinen, daß die Stettiner Waldenserinquisitionsfragmente, die heute in der Herzog-AugustBibliothek in Wolfenbüttel aufbewahrt und in dem unten zitierten Buch von Kurze ediert und zum Teil auch reproduziert wurden, damit zusammenhängen können. Beim genaueren Vergleich (da die Texte aus der gleichen Zeit herrühren, kann man mit dem sonst möglichen Schrift- und Duktuswechsel im Laufe einer eventuell längeren Zeitspanne kaum rechnen) stellt man jedoch fest, daß es nicht der Fall ist, obwohl in der Stettiner Kampagne der Prager Erzbischof als einer der spiritus agentes galt. Gewisse Ähnlichkeiten im Strukturaufbau der Verhöre mit unserem Fragment B sind meiner Meinung nach durch die gleichen Ausgangspunkte sowie die allgemeinen Vorschriften zu erklären. Eher ist die enge Verwandtschaft zwischen den Schreiberhänden des Fragmentes B und C zu merken, obwohl ich auch hier skeptisch bin und daraus keine Schlüsse ziehen möchte.

Sorge um ein derartiges Kulturgut zur Zeit Josefs II., auf der anderen Seite die Bemühungen des Klosters Strahov selbst. Vgl. übrigens auch die vorherige Anm.

$14 \mathrm{Vgl}$. die zusammengestellten Nachrichten Patschovskys in seinen Quellen (wie Anm. 4) $127 \mathrm{ff}$.

$15 \mathrm{Ob}$ es ein Zufall ist, daß die meisten Fragmente der älteren, von A. Patschovsky bearbeiteten Protokolle eben in Heiligenkreuz überliefert sind, in der ältesten Zisterze des österreichisch-böhmischen Raumes also, die als Mutterkloster zahlreicher böhmischer Stifte galt, jedoch nicht von Königsaal, ist nicht zu ermitteln. Da jedoch Heiligenkreuz auch weiterhin enge Kontakte pflegte und sicher als Zufluchtstätte für mehrere böhmische Zisterzienser galt (vgl. Jaroslav Kadlec, Katoličtí exulanti čeští doby husitské [Praha 1990] 54 ff.), ist hier ein direkter Kontakt nicht auszuschließen. 
Nun also zum konkreten Material, das zwei Typen von Verhören bietet. Beide sind freilich diplomatisch als Originale zu bezeichnen. Während Fragment A etliche Striche bzw. gleichzeitige Marginalien aufweist, ist Fragment B zügiger geschrieben und bringt lediglich einen Strich und keine Marginalien. Auch Wasserzeichen gibt es nicht.

Als Fragment A bezeichne ich dasjenige Bruchstück, welches ein Verhör zum Inhalt hat, das schon auf den ersten Blick als solches direkt auf eine konkrete Person zielt oder aber auf eine ganz konkrete causa orientiert ist. Dies geht eindeutig sowohl aus dem Kontext als auch aus der Tatsache hervor, daß die Einzelaussagen marginal numeriert werden und so zweifelsfrei aufzeigen, daß sie innerlich und unmittelbar zusammenhängen. Mehr als die ganze Recto-Seite füllt der Absatz 25 aus, dessen Anfang allerdings fehlt; die Verso-Seite beinhaltet Artikel 26, 27 und die beiden ersten Zeilen des folgenden, also 28. Artikels. Da die Numerierung in arabischen Ziffern vorgenommen wurde, die um diese Zeit in der Praxis nur ganz selten auftauchen und wohl modernere Formen aufweisen (da nur ganz wenig Material zur Verfügung steht, sollte man vorsichtig sein), ist nicht ausgeschlossen, daß die ganze Numerierung später, jedoch wiederum nicht allzu spät, nachgetragen wurde ${ }^{16}$. In jedem Fall macht schon sie sehr wahrscheinlich, daß das ganze Protokoll eine einzige konkrete causa umfaßte. An der Reversseite in margine hoch links steht schließlich, ebenfalls in arabischen Ziffern, jedoch aus jüngerer Zeit, die Paginierung, nämlich die Nummer 27. Das entspricht übereinstimmend auch der Numerierung der einzelnen Artikel, deren Umfang zwischen ein paar Zeilen und mehr als einer Seite schwankt, durchschnittlich demzufolge etwa je eine Seite beträgt.

Worum es inhaltlich geht, läßt sich aus dem sonst sehr bruchstückhaften Material ziemlich eindeutig erkennen. Es handelt sich um das Verhör eines Gefährten des berühmten Prager Frühreformators, des Pariser Magisters Matthias von Janov. Dies ist nicht allein wegen der Person interessant, ja wichtig, sondern es ermöglicht zugleich eine zumindest engere Rahmendatierung des sonst zeitlich nicht fixierten Verfahrens. Da Matthias von Janov hier einmal mit seinem vollen Namen und darüber hinaus mehrere Male nur mit dem Vornamen erscheint, ist klar, daß es sich um die Zeit um oder besser vor 1393 handeln muß ${ }^{17}$. Sicher gehen wir nicht fehl, wenn wir diese Verhöre mit den dogmatisch-theologischen Zusammenstößen des Matthias mit dem Prager Erzbischof am Ende der achtziger und zu Beginn der neunziger Jahre des 14. Jahrhunderts in Zusammenhang bringen, die aus anderen Quellen wenigstens andeutungsweise bekannt sind ${ }^{18}$. Doch hier erfahren wir bedeutend mehr in dem Sinne, daß wir die Möglichkeit haben, direkt in die

16 Vgl. dazu auch Adriano Cappelli, Dizionario di abbreviature latine ed italiane (Milano 61961) $422 \mathrm{ff}$.

17 Über ihn bis heute richtungsweisend Vlastimil Kybal, M. Matěj z Janova. Jeho život, spisy a učení (Praha 1905), wo wohl nur der falsche Sterbetag (richtig: 30.November 1393) zu verbessern ist. Neuere Literatur in Milan Machovec, Jana Nechutová, Mladá Vožice k poctě Matěje z Janova (Mladá Vožice 1994).

18 Bei Kybal, (wie vorherige Anm.), $20 \mathrm{ff}$. 
Dinge „einzutreten“. Mehr noch: Neben dem bisher Bekannten über das das erzbischöfliche Gericht informiert, finden wir hier einen unmittelbaren Beweis dafür, daß Janovs Aktivitäten ein breiteres Echo und den Verdacht auch anderer kirchlicher Institutionen weckten, da es sich bei ihm nicht, wie meist vorausgesetzt, um einen isolierten Einzelgänger handelte, sondern um eine Person, die mehrere Kollegen, ja Anhänger besaß, die mit ihm in regem, geistlichem Austausch standen und aufgrund ihrer Kontakte eine größere Gefahr verkörperten, als nur ein „Einzelgänger" für die kirchliche Hierarchie. Freilich könnte eingewendet werden, es sei fraglich, ob es sich hier unbedingt um inquisitorische Akten handelt und nicht um das reguläre erzbischöfliche Gericht. Da das Fragment allzu knapp ausfällt und auch die diesbezüglichen Formulierungen nicht gerade als eindeutig gelten können, muß hinsichtlich des Ergebnisses eine gewisse Vorsicht geübt werden, doch schließe ich nicht aus, daß es sich eventuell um das Verhör vor dem Konsistorialgericht handelte, worüber wir an anderer Stelle informiert werden.

Wäre dem in der Tat so, schiene es am plausibelsten, wenn man unser Fragment mit den Ereignissen des Jahres 1392, als Matthias zweimal vor den Generalvikaren erscheinen mußte, in Verbindung setzte ${ }^{19}$. Wenn wir seinen Inhalt wenigstens knapp resümieren wollten, so müßte wohl konstatiert werden, daß es sich um das Verhör eines nicht näher einzuordnenden Mönches (vermutlich eines AugustinerEremiten?) über etliche theologische Fragen handelte, wobei es besonders um die Antichristlehre, zugleich jedoch auch um mehrere mystische Autoren und deren Schriften - u.a. Johannes Rupescissa (dessen Werk sich der Verhörte aus der Vorlage eines Breslauer Vikars abgeschrieben hatte), die Revelationes b. Brigitte und Hildegardis und auch Marco Polo, welcher hier als Marcus de Veneciis, der über die Machometaner schreibt, - ging. Auf die Machometaner lief das Gespräch aber auch sonst mehrfach hinaus. Nicht unerwähnt bleiben dürfen aber auch die Kontakte des Verhörten, über die er nicht allein innerhalb Prags, sondern auch außerhalb der Landesmetropole verfügte: So führte zum Beispiel der Büchertausch mit dem Vikar der dortigen (Kathedral?)kirche direkt nach Breslau.

Was die inhaltliche und überlieferungsgeschichtliche Seite betrifft, haben wir es hier mit einem gewissen Paradox zu tun. Während das Verhör im Fragment A für die geistige Geschichte Böhmens von relativ großer Bedeutung sein mag, erscheint es für die uns hier vorrangig interessierende Frage des Ketzertums im Lande doch ein wenig nebensächlich. Vollkommen umgekehrt dann kann man aber das zweite Fragment, Bruchstück B, charakterisieren. Obwohl die Verhörten völlig unbedeutende Personen waren und ansonsten quellenmäßig nicht weiter zu erfassen sind, führen uns ihre Verhöre dennoch die bisher geradezu vergessene, ja bisweilen negierte Dimension bedeutend klarer vor Augen. Der Text enthält zwei Verhöre, die sich selbst expressis verbis als inquisitorisches Verfahren deklarieren und

19 Die Darstellung bei Emil Valasek, Das Kirchenverständnis des Prager Magisters Matthias von Janow (1350/55-1393). Ein Beitrag zur Geistesgeschichte Böhmens im 14. Jahrhundert (Roma 1971) $53 \mathrm{ff}$. bietet Kybal gegenüber nichts Neues. Vgl. auch Ruben E. Weltsch, Archbishop John of Jenstein 1348-1400 (The Hague, Paris 1968) $166 \mathrm{ff}$. und Jaroslav V.Polc, Svatý Jan Nepomucký 1 (Řím 1972)164ff. 
die den Spuren des Waldensertums nachgingen. Alle konkreten Namen, die hier auftauchen, lassen sich schwerlich in dem bekannten Material verankern, und wenn dies dennoch den Anschein erweckt, so ist es stets fraglich, ob es sich nicht um eine zufällige Ähnlichkeit handelt ${ }^{20}$. Auch hier erweisen sich die chronologischen Angaben als sehr dürftig. Eigentlich taucht nur einmal die Angabe des Monatstages (8. Juni) auf, während in der Jahresangabe nur der Hinweis auf die vorherige, freilich nicht erhaltene Jahresdatierung vorkommt. Aber dennoch sind wir nicht vollkommen hilflos, obwohl eine gewisse Vorsicht angebracht scheint. Bei der Besprechung der Stellungnahmen der Waldenser zu verschiedensten Festivitäten der katholischen Kirche findet im ersten Verhör auch der annus jubilaeus Erwähnung. Dies weist deutlich auf jenes Fest hin ${ }^{21}$, das gerade im Jahre 1393 in Prag, weil vom Papst kurz vorher eben dem böhmischen Königreich erteilt, ein großes Echo fand, weil es sich zu einem handfesten Politikum entwickelte ${ }^{22}$. Aber auch wenn diese Datierung nicht stimmen sollte, bleibt das Ende des 14. Jahrhunderts als Entstehungszeit des Bruchstücks B, d.h. zugleich des zuständigen Inquisitionsprotokolls, gültig. Und das ist von Bedeutung, denn auf diese Weise wird die ununterbrochene oder wenigstens die sich immer erneuernde Existenz der Inquisitionstätigkeit eindeutig bewiesen bzw. bestätigt. An dieser Stelle muß wenigstens rahmenweise auch das andere Fragment der böhmischen Inquisitionstätigkeit, nämlich das in der Prager Nationalbibliothek aufbewahrte und oben schon avisierte „Truhlár̆“-Bruchstück, ins Spiel gebracht werden ${ }^{23}$. Ich bezeichne es als C.

Was seine Ausmaße anbelangt, so können sie, wenngleich ein bißchen kleiner als die der Bruchstücke $\mathrm{A}$ und $\mathrm{B}$, nicht als richtungsweisend gelten, da das entsprechende Papierblatt abgeschnitten ist. Das Spiegelbild jedoch zeigt sich als ungefähr deckungsgleich. Das Papier trägt als Wasserzeichen den Ochsenkopf der Zeit und deklariert sich als letztes Blatt des ansonsten verlorengegangenen Ban-

20 Das betrifft nicht nur die Namen der einfachen Waldenser, was nur allzu verständlich erscheint, sondern auch diejenigen der Zeugen der einzelnen Inquisitionsverhöre, die doch mehrere Spuren in den zeitgenössischen Quellen hinterlassen konnten, so z.B. der öffentliche Notar Matthias de Wriczik, von dem sich ebenfalls keine weitere Spur findet (vgl. Josef Nubliče $k$, Veřejní notár̆i v českých městech, zvlášš v městech pražských [Praha 1940] $80 \mathrm{ff}$.).

${ }^{21}$ Es verdient betont zu werden, daß in den sehr exakt bearbeiteten Sach- und Wortregistern beider (vgl. Anm. 5) Editionen Patschovskys dieser Begriff nicht vorkommt, obwohl die Institution des Jubiläumsjahres bereits berühmt war.

22 Über dieses Fest, das gerade im Streit zwischen dem Prager Erzbischof Johann von Jenstein und dem König eine gewisse Rolle spielte, vgl. die Bulle Bonifaz' IX. vom 15. Januar 1393 (ediert in Monumenta Vaticana res gestas Bohemicas illustrantia 5, hrsg. von Camillus Krofta [Pragae 1903] Nr.669) und Jiř́ Spěváček, Václav IV. 1361-1419 (Praha 1986) 218f. und 225.

${ }^{23}$ Hrsg. von Josef Trublár̆, Paběrky z rukopisů klementinských Nr.26: Zlomky akt inkvisice Waldenské $v$ Čechách $z$ let 1393-1394, in: Věstník České akademie věd a umění 8 (1899) 353-355. Die heutige Sign. VII A 16 Nr.3, früher zur Hs. V H 8, als Vorsatzblatt zugeklebt (vgl. Josef Trublär, Catalogus codicum manu scriptorum latinorum qui in C.R. bibliotheca publica atque universitatis Pragensis asservantur 2 (Pragae 1906) Nr.996 und 1224. In Beilage $\mathrm{C}$ wird bis auf gewisse Einzelheiten der Abdruck Trublärs wiedergegeben. 
des, da seine Verso-Seite - nachdem die Recto-Seite bis zum Schluß beschrieben wurde - bereits ursprünglich leer blieb, was wohl nur soviel bedeuten kann, daß der Eintrag den entsprechenden Band abschloß. Die Handschrift, von der das Fragment abgetrennt wurde und die dem 15. Jahrhundert angehört, zählte wohl bereits zur alten Ausstattung des Prager Jesuitenkollegiums des hl. Clemens und ist deshalb ursprünglich der Universität zuzuschreiben, womit auch der Inhalt im Einklang steht, da das ganze Buch mehrere Werke Johann Gersons beinhaltet, u.a. auch den Erlaß des Konstanzer Konzils gegen die communio sub utraque vom 20. August 1417. Truhlár datierte in seiner Edition dieses Inquisitionsprotokollfragment in die Jahre 1393-1394, so daß auf den ersten Blick die Vermutung naheliegt, daß es sich in B und C um Fragmente ein und desselben Bandes handeln könnte. Bei näherer Analyse zeigt sich jedoch, daß dies aus verschiedenen Gründen (unterschiedliche Schreiberhände, andere Begleitpersonen und ähnliches) kaum akzeptabel scheint. Zuerst jedoch zur Datierung des Stückes C, das nach Truhlář in die Jahre 1393-1394 fällt.

Welche Gründe mögen den Herausgeber hierzu veranlaßt haben? Im Grunde genommen keine überzeugenden, da es sich hier eigentlich nur um eine Parallele zur Brandenburger Inquisition handelt, die zu Truhlárs Zeiten eben in die Jahre 1393-1394 datiert wurde. Heute weiß man jedoch, daß diese Inquisition mindestens bereits 1392 einsetzte und daß in ihr eigentlich keine unmittelbaren Bezüge zu Böhmen festzustellen sind ${ }^{24}$, so daß diese Parallele vollkommen wegfällt. Welche anderen Zeitangaben können also hinzugezogen werden? Aus der "großen“ Geschichte sind es folgende: das Pontifikat Bonifaz' IX. (1389-1404) und das des Prager Erzbischofs Johann von Jenstein (1379 - Januar 1396), aus der „kleinen“ wohl die Existenz und Amtsausübung des öffentlichen Notars Andreas Petri de Jauer, der sonst ab 1390 bezeugt ist ${ }^{25}$, und vornehmlich dann diejenige des Pfarrers von Sušany (Zuscha, Bez. Komotau) in Nordböhmen, welcher dieses Benefizium im Januar 1389 erhielt ${ }^{26}$. Daraus geht hervor, daß als Termin a quo das Jahr 1389 und ad quem das Jahr 1395 gelten müssen, was jedoch die Datierung 13921393 nicht ausschließt, aber auch nicht unbedingt zwingend macht. Dies wiederum bedeutet, daß es noch lange nicht logisch, ja aus den oben erwähnten kodikologischen Gründen fast unmöglich ist, daß B und $C$ aus einem Band stammen, ja, daß aufgrund des Unterschiedes der Schreiberhände sowie etlicher weiterer formaler Ungleichmäßigkeiten, die Sache ziemlich unwahrscheinlich sein dürfte.

24 Vgl. neuerdings Dieter Kurze, Quellen zur Ketzergeschichte Brandenburgs und Pommerns (Berlin, New York 1975) (=Veröffentlichungen der Historischen Kommission zu Berlin, Bd.45) $18 \mathrm{ff}$. und $77 \mathrm{ff}$.

$25 \mathrm{Vgl}$. Nubliček, Veřejní notár̆i (wie oben Anm. 20) zvláště v městech pražských (Praha 1940) 74 und 110 Nr.337. Er wird hier gleichzeitig als Beamter der Juristen-Universität angeführt (vgl. auch Marie Haasová-Jelinková, Správa a kancelář pražské university v první době jejího trvání [Praha 1949] 41 ff. Das parallel erschienene Buch von Fritz Luschek, Notariatsurkunden und Notariat in Schlesien von den Anfängen (1282) bis zum Ende des 16. Jahrhunderts [Weimar 1940] revidiert ihn nicht).

26 Vgl. Libri confirmationum ad beneficia ecclesiastica Pragensem per archidioecesim 3-4, hrsg. von Josef Emler (Pragae 1879) 205. 
Das unterstützt letzten Endes auch die unterschiedliche Provenienz, da - wie schon erwähnt - Fragment $C$ seinen Weg ziemlich bald in eine nicht näher bekannte Kollegienbibliothek der Prager Universität gefunden hat. Wer allerdings der erste Nachbesitzer der Gerson-Handschrift noch vor deren „Bibliotheksfund" war, ist nicht zu ermitteln. Das alles, d.h. die unterschiedliche Überlieferung, erhöht die Bedeutung beider Fragmente, da wir jetzt mit der Existenz mehrerer, mindestens zweier paralleler - oder eher anknüpfender - Inquisitionsbände in der ersten Hälfte der neunziger Jahre in Böhmen, genauer in Prag, rechnen müssen. Dies bedeutet zwangsläufig auch, daß sich damals die Inquisition in der Prager Diözese sehr massiv entfaltet hat, was uns gestattet, ihre unheilvolle Tätigkeit erst jetzt in vollem Umfang einzuschätzen.

Nun jedoch zurück zum Inhalt des Fragments $B^{27}$. Wie eben angedeutet, haben wir es hier mit zwei Verhören zu tun. Das erste ist vollständig erhalten, dem zweiten fehlt der Schluß. Die eigentliche Inquisition realisierte sich freilich in beiden Fällen in Prag, was zwar ohne weiteres vorauszusetzen ist, jedoch auch direkt im ersten Verhör erwähnt wird (I-27: quod prius fuerit hic Prage). Da zugleich über die Vorladung gesprochen wird, ist fast selbstverständlich vorauszusetzen, daß hier eine gewisse „Vorarbeit“ geleistet worden war, da diese Vorgangsweise sonst nicht zustande gekommen wäre.

Bei beiden Verhörten handelte es sich um Frauen, und beide stammten aus der gleichen Ortschaft, nämlich aus Komotau, also aus der Stadt des Deutschen Ordens, der dort seine wichtigste Kommende in der Ballei Böhmen besaß, die darüber hinaus als Sitz des Landkomturs diente ${ }^{28}$. Daß Komotau damals schon nahezu vollständig deutschsprachig war ${ }^{29}$, liegt auf der Hand. Im übrigen bestätigen auch die im Verhör vorkommenden anderen Namen diese Annahme zweifelsfrei, andererseits belegen die Kontexte, die hier eindeutig hervortreten, daß die Migration der Mitglieder der waldensischen Kommunität - wie freilich vorauszusetzen war - als ziemlich groß bezeichnet werden darf.

Eine Marginalie muß jedoch erwähnt werden, da ein Umstand auffällig zu sein scheint. Wie oben angeführt, fand der erste große Inquisitionszug in der Spätzeit Johanns von Luxemburg in Südböhmen statt, genauer in der Umgebung von Neuhaus, wo es ebenfalls eine Kommende des Deutschen Ordens gab ${ }^{30}$. Daher ließe sich vermuten, daß der Deutsche Orden bei dieser Ketzerbekämpfung eine gewisse, nicht näher definierbare Rolle spielte. Freilich können beide Eventualitäten in Erwägung gezogen werden, daß nämlich entweder der Orden der Recht-

27 Im folgenden zitiere ich die Verhöre mit den Nummern 1 und 2 mit beigefügten Zeilen direkt in Klammern im Text.

28 Vgl. Josef V.Šimák, České dẹjiny I-5 (Praha 1938) 618 und Josef Hemmerle, Die Deutschordens-Ballei Böhmen in ihren Rechnungsbüchern 1382-1411 (Bonn 1967) 25.

29 Über die nationalen Verhältnisse vgl. Ernst Schwarz, Volkstumsgeschichte der Sudetenländer, Teil 1: Böhmen (München 1965) (Handbuch der sudetendeutschen Kulturgeschichte, Bd.3) $168 \mathrm{ff}$., der jedoch zumindest eine ganz bescheidene tschechische Minderheit zuläßt, die aber eher in zahlreichen umliegenden Dörfern zu finden war.

30 Vgl. Šimák, České dějiny, I-5, 1143 ff. und Hemmerle, Die Deutschordens-Ballei nach Register, Stichwort "Neuhaus“. 
gläubigkeit in der Umgebung seiner Güter erhöhte Aufmerksamkeit widmete, oder aber, daß umgekehrt sich seine Herrschaft in Glaubensfragen derart tolerant gestaltete, daß dort das Waldensertum gedeihen konnte. Bei dieser rein logischen Konstruktion muß jedoch höchstwahrscheinlich der ersten Annahme Vorzug eingeräumt werden. Aber zurück zum Inhalt des entsprechenden Protokolls.

Beide Eltern des verhörten Mädchens, das Margaretha Offengrabe hieß, aus Komotau stammte und sonst nirgendwo belegt ist ${ }^{31}$, werden genannt: Nikel Grellenhart und die nicht näher bezeichnete Dorotbea (I-4,5), die allerdings mit der waldensischen Sekte nichts zu tun hatten. Margaretha selbst wurde für das Waldensertum durch einen gewissen Dressler, ebenfalls aus Komotau (I-6), gewonnen, was ungefähr fünf Jahre vor dem Verhör geschah. Eine wichtige organisatorische Rolle spielten hier der Kaadener Bürger (?) Petrus Ungarus und die Familie seines gleichnamigen Sohnes. Auch die zweite Verhörte hieß Margaretha und war die Witwe des Petrus Sleyffer de Commetaw, geboren in einem Dorf rund $5 \mathrm{~km}$ von Komotau entfernt (Eidlitz-Údlice, im Text Ewdlicz II-3). Ihre Eltern hießen Wenczeslaus Krymaw und Crisana. Auch sie gehörten nicht den Waldensern an, sondern Margaretha wurde in die Sekte durch die inzwischen verstorbene Chunne Krewsynne eingeführt (II-5f.), wo auf sie später vornehmlich der Komotauer Andreas Dressler (II-9) Einfluß ausübte. Im Laufe der Jahre knüpfte sie Kontakte nicht nur zu etlichen Einheimischen (so zu Hicke Mulner ante Comotaw II-12f.), sondern auch zu mehreren aus dem Ausland stammenden Personen: Nicolaus de Wienna, Nicolaus de Stiria (II-11f.). Dieser geographische Horizont ist nur sehr bescheiden, doch deutet er zumindest die ziemlich weiten räumlichen Kontexte an, überraschenderweise allerdings nicht zu anderen (früher) nachweisbaren waldensischen Zentren in Prag bzw. in Südböhmen. Aber das alles ist wohl eher der fragmentarischen Überlieferung zuzurechnen, da uns auch das Fragment $\mathrm{C}$ nicht wesentlich weiter hilft. Da jedoch dessen einzige geographische Bezeichnung sich konkret auf Sušany-Zuscha (das rund $10 \mathrm{~km}$ östlich von Komotau gelegene Dorf) bezieht, scheint es plausibel, vorauszusetzen, daß diese Landschaft auch nach den Inquisitionen in früheren Zeiten waldensisch blieb, da es dort nicht gelang, diese Häresie auszurotten ${ }^{32}$.

Nach dem räumlichen Aspekt soll auch noch der inhaltliche kurz zu Wort kommen. Von den vermutlich einfachen Frauen konnte man kaum Antworten auf kompliziertere Sachverhalte erwarten, so daß es in den Verhören vornehmlich um zwei Fragenkreise ging, die mit knappen Worten folgendermaßen charakterisiert werden können: 1) Wie gelangte man zur waldensischen Lehre, wer war daran beteiligt, wo fanden die Zeremonien statt und wie sah es mit dem Ausweg aus ihr aus? 2) Inwieweit waren die Verhörten mit der waldensischen Lehre sozusagen „im Praktischen“ vertraut? Gehen wir nun die Antworten auf beide kurz durch.

Die erste Frage zerfällt in mehrere ziemlich eigenständige Unterfragen, die kurz

31 Das ist eigentlich in solchen Fällen fast allgemein üblich, deshalb bietet sich hier auch ein bescheidenes, jedoch neues Material selbst für die Sprachforscher.

32 Vgl. Patschovsky, Quellen (wie Anm. 4), 249, jedoch eher andeutungsweise. 
mit den Worten „Wie? Wer? Wo? “ umschrieben werden können. Zunächst ist der erste Aspekt zu besprechen, und dies bedeutet, eingangs nach dem ersten Kontakt mit der waldensischen Lehre zu fragen, da diesbezüglich wahrscheinlich nicht die familiären Verhältnisse ausschlaggebend waren. Denn in beiden Fällen wird ausdrücklich darüber referiert, daß die Eltern mit der Sekte nichts gemein hatten, bei der Witwe wohl auch der verstorbene Gatte nicht. Die Voraussetzung, daß die beiden Frauen mit Namen Margarethe auf diese Weise ihre Verwandten schützen wollten, scheint mir nicht überzeugend zu sein, da sie höchstwahrscheinlich (der Gatte der anderen Margarethe sicher) schon tot und deshalb nicht direkt betroffen waren. Dem zweiten Verhör können wir jedoch zumindest andeutungsweise entnehmen, daß dem Toten doch noch die postmortale Strafe drohte, da man nach dem Friedhof der Frau, die Margaretha bei den Waldensern eingeführt hatte, fragte.

Die Anfragen betreffs der theologischen Probleme haben sich aus begreiflichen Gründen auf einfachste Sachverhalte beschränkt, so besonders auf die Heiligenverehrung, auf die Nichtexistenz des Fegefeuers, auf das Fasten und den konkreten Verlauf der Absolution. Auch die Versammlungen der Sektenmitglieder sowie ihre Struktur fielen in den Fragenkatalog. Die einzelnen Gebete wurden genau unterschieden. Während Pater noster und Credo akzeptiert wurden, verwarf man das Ave Maria. Schließlich kam auch die Reliquien- und Bilderverehrung zur Sprache, wobei beides nur unter der Voraussetzung angenommen war, daß es propter Deum und nicht ad laudem sanctorum geschehen war. Natürlich wurde auch der Eid als Sünde verworfen. Wohl beiden Frauen stellte man schließlich die Frage, ob sie die waldensische Lehre aufzugeben gedächten. Den konkreten, eventuell daran anknüpfenden Verlauf kennen wir jedoch nur bei Margaretha Offengrabe, die die Frage bejahend beantwortete und schon im vorhinein zu der, freilich nicht näher spezifizierten, Strafe Zustimmung äußerte. Man sprach jedoch ganz allgemein über Reue, so daß zu vermuten ist, daß hier nicht mit schweren Folgen zu rechnen war. Da im zweiten Fall der Schluß des Verhöres fehlt, können wir wohl mit größter Wahrscheinlichkeit einen analogen Fortgang der Dinge voraussetzen.

Es ließen sich noch zahlreiche weitere Teile der waldensischen Glaubenslehre anführen, doch für die Sektenlehre sind diese im Grunde genommen - wie nicht anders zu erwarten - ziemlich belanglos. Zusammenfassend darf also geschlußfolgert werden, daß beide Fragmente trotz all ihrer Dürftigkeit völlig unterschiedlich bewertet werden müssen. Fragment A zeugt vom energischen Kampf der böhmischen Kirche gegen das gelehrte, literarische Ketzertum, das in Kürze in Hussens Reformation Fortsetzung finden sollte, von einer Auseinandersetzung, die schon bei den ersten reformerischen Anzeichen oder besser beim Auftauchen der aus der Sicht der Kirche irrigen theologischen Ansichten, massiv geführt wurde, wobei die Kirche die Verdächtigten in möglichst breiten Zusammenhängen verfolgen ließ.

Bruchstück B liefert dann den willkommenen Beweis, daß das Waldensertum um die Jahrhundertwende immer noch - oder schon wieder? - ziemlich verbreitet 
war und die Kirche versuchte, dieses energisch auszurotten. Während in der Spätzeit Johanns von Luxemburg und später das Hauptfeld der Inquisition wohl im Süden des Landes und bei der deutschen Bevölkerung festzustellen ist, handelt es sich bei unserer Quelle zwar ebenfalls um deutsche Mitglieder der Sekte, allerdings am entgegengesetzten Ende des Landes, wenngleich Kontakte der Verhörten zum Süden auch hier zu bemerken sind. Die konkrete Rolle des Deutschen Ordens, auf die wir verwiesen haben, galt hier als präsent. Mit anderen Worten bedeutet dies, daß das Waldensertum in Böhmen zumindest unter den Bewohnern deutscher Zunge als ziemlich verbreitet galt und als kaum ausrottbar zu bezeichnen ist. Das wirft weitere, obwohl eigentlich indirekte Streiflichter auch auf die tschechische Reformpartei, und für die Genesis der hussitischen Bewegung als Ganzes vermag dies eine nicht zu vernachlässigende Quelle darstellen. Aber dies alles zu bewerten, muß einer anderen Gelegenheit und wohl auch den sachkundigen Spezialisten, die sich mit breiteren Zusammenhängen befassen, überlassen werden. Hier sollte eine (eigentlich zwei) bisher nicht bekannte Quelle vorgestellt werden, die jedoch noch weiteren Analysen unterzogen werden müßte. Quod erat demonstrandum. 


\section{Edition*)}

\section{Fragment A}

pag. ${ }^{\mathrm{r}}$

(1) deponens habeat copiam bulle, sed de solucione eorundem dicit

(2) iterum, $\mathrm{se}^{\mathrm{a}}$ ) indigere assistenciam intelligencium et copiam librorum et

(3) de hiis sicud de aliis. Hinc inde de eisdem ubi expedit scribet ${ }^{b}$ )

(4) et ubi magis loqui, respondere velit intelligentibusc) devotis.

(5) Et quod liber sigill(atus) /est/ propter stult(os)d), qui forte legissent, sit liber Johannis

(6) de Rupescissa ${ }^{1)}$ et quod ipse eum habeat proprium et quod in eodem contineture)

(7) materia de Antichristo, et quod eundem librum portasset magistris suis non re-

(8) quisitis, et quod habeat eum non ad approbandum sed ad se exercitandum,

(9) sicud eciam mala possunt studeri, ex quo malum non emicatur nisi congnotis /?/;

(10) et quod Johannes de $\mathrm{f}^{\mathrm{f}}$ Rupescissa predictusg) fuerat frater ordinis

(11) Minorum et quod ipsum rescripsisset ex libro cuiusdam vicarii ecclesie

(12) Wrat(islaviensis), Achacius nomine ${ }^{2)}$, quem, credit, adhuc exemplar habere;

*) Bei der Herstellung des äußerst schwierigen Textes, der auch weiterhin sicher noch verbesserungsbedürftig ist, bin ich zwei Kollegen für ihre große Hilfe zu tiefem Dank verpflichtet: Frau Dr. Anežka Vidmanová und besonders Prof. Dr. Alexander Patschovsky, dessen Hinweise auch etlichen Stellen im Text zugute kamen. Die Fehler und zweifelhaften Lesungen sind jedoch nur mir zuzuschreiben.

1) Johannes von Roquetaillade OMin., + nach 1365.

2) Der Name war nicht zu ermitteln.

a) Interlinearer Nachtrag durch gleiche Hand.

b) Vorgehendes scribere fast völlig ausradiert.

c) Vorgehendes inde gestrichen.

d) Ein sechszeiliger kaum lesbarer marginaler gleichzeitiger Vermerk: Et sigillasset solummodo (?)// spiritualiter(?) propter unum, qui sibi aliam intelligenciam in eodem volumine scripserat; et quod idem sigill(atus) liber erat exemplar vicarii alia ////in eodem volumine scripserat et quod idem sigillorum liber erat exemplar vicarii.

c) Es soll wohl quem heißen.

f) Folgendes $\mathrm{P}$ gestrichen.

g) Folgendes wiederholtes predictus gestrichen. 
(13) et quod de libro secretissima sacre theologie continent $\left.(\mathrm{e})^{\mathrm{h}}\right)$ nichil sciat $\left.{ }^{\mathrm{t}}\right) \cdot$ Ac

(14) quod, quomodo visiones sanctek) Brigittel ${ }^{\mathrm{l} 3)}$ sibi deserviant,

(15) quas legit ut alter christianus de ista materia scrutanter, sed sancte ${ }^{\mathrm{k})}$ Hyldegardis

(16) virginis, amice sancti Bernhardi, canonizate ab Eugenio papa ${ }^{4}$ ), non vidit,

(17) sed audiverit, quod essent in Brvnovia circa Pragam ${ }^{5}$; et quod scripsisset

(18) de ista materia. Et quod $\mathrm{M}^{6}$ ) provin(cialis) promisisset sibi ordinare eos. De

(19) Machometo nichil sciat nisi sicud legerit in libro, qui vocatur Marcus

(20) de Veneciis ${ }^{7}$ ). Sibi intellexit, quod ille Machometis multas gentes

(21) reduxit de ydolatria, saltem pura ydolatria, ad cultum

(22) legis Moy(sis) et in parte ad cultum legis Christi. Ex quo consideravit,

(23) quod in illa terra missis ${ }^{\mathrm{m}}$, multa sit et operari(i) pauci ${ }^{8}$ ); et quod multis

(24) se ocupasset, quomodo per graciam Dei homines ibi existentes possent

(25) reduci ad unitatem fidei, sicud sunt partes Jerosolimitane, Babilonie,

(26) Arabie, Indie et sic de aliis. Quem librum habuit M(agister) mense. Et quod ipsemet eciam

(27) habeat aliqua excerpta de Machometo, sicud quidam frater heremitarum sancti

3) Birgitta von Schweden, + 1373, kanonisiert 1391.

4) Hildegard von Bingen,+ 1179, wurde jedoch erst ab Anfang des 15. Jh. als Heilige verehrt. Die Erwähnung der angeblichen Kanonisation durch Eugen III. (1143-1152) bezieht sich wohl auf die Approbation ihres Liber scivias durch diesen Papst auf der Trierer Synode von 1147/8. Vgl. auch H. Grundmann, Ausgewählte Aufsätze 1, Religiöse Bewegungen (Schriften der MGH 25,1), Stuttgart 1976, S. $188 \mathrm{f}$.

5) Das älteste Benediktinerkloster Böhmens, damals unweit westlich von Prag, heutzutage in einem Stadtteil Prags.

6) Obwohl so gut wie sicher ist, daß es sich um einen Dominikanerprovinzial handeln muß, treffen wir in der einzigen Provinzialenliste keinen solchen (vgl. Vladimír J. Koudelka, Zur Geschichte der böhmischen Dominikanerprovinz im Mittelalter I - Provinzialprioren, Inquisitoren, Apost. Pönitentiare, Archivum fratrum Praedicatorum 25, 1955, S. 75 ff., vornehmlich S. 80). Der plausible Ausweg existiert doch, nämlich, daß der Provinzial Nikolaus hier in der tschechischen Form Mikuláš erwähnt wird. Kann jedoch auch als M(agister) provin(cialis) gelesen werden.

7) Marco Polo (+ 1324) und seine berühmte Reisebeschreibung.

8) Matth. 9,37 = Luc. 10,2.

h) Vor dem Wort nichil irrtümlicherweise libro noch einmal geschrieben.

i) Hierher gehört sechszeilige und gleichzeitige, jedoch zum Teil unlesbare Marginalie: sed credat, quod observator eius, qui illa exemparia habuerit ecclesiam (?)//sexternulo, ubi excerpta monachi in canoni/bus/ continentur; quia ibi continentur ista verba secreta ewangelice prophecie.

k) Sancte interlinear.

l) Folgendes et virginis Hyldegardis an der Zeile gestrichen.

m) Wohl messis. 
(28) Augustini scripserat Karolo 4 Romanorum imperatorin),

(29) Item interrogatus, an habeat aliquos plures libros sibi in hac materia solum

(30) servientes, et presertim quod sibi M. Mathias de Janow ordinaverat

(31) de quibus ${ }^{\circ}$ ) longinquis partibus, respondit, quod nullos nisi sexternulos, quos prius

(32) voluntarie portaverat M/agistro/ provin/ciali/ et quod non habeat nec habuerit alium.

(33) Pro hoc M. Mathias ${ }^{10)}$ direxerat et quod audiverit, quod M. Mathias,

pag. ${ }^{\mathrm{v}}$

(1) sacre theologie magister, confessor sancte Brigitte ${ }^{11)}$. Ibidem scripserat de

(2) Antichristo, sicud remittit ad eum sancta Brigitta cum libris suis

(3) et quod de biblia adduceret, scripturis indigeret et sic de aliis.

(4) (26) Item interrogatus, qui sint, qui materiam istam inordinate prosequuntur et

(5) quem ipsemet eam inordinate prosequeretur, puta de Antichristo,

(6) responditp) ad illam questionem sicud in protestacione sua scripsit condic/ ion/aliter,

(7) quod si magistri invenisse/n/t materiam illam malam, quod tunc ordinate fuisse $/ \mathrm{n} / \mathrm{t}$

(8) prosecuti eam redargucione eo melius et eo cicius et sic de aliis. $\mathrm{Nec}$

(9) sciat se adhuc inordinate prosequi et prosecutum fuisse.

(10) (27) Item interrogatus, quomodo reputet homines non sufficienter doctrinis

(11) et scripturis aliis munitos ad dirigendum facta sua in Deum

(12) et se preparandum contra malum, quam ex ista sic occulta materia, et quare plus

(13) ex ista quam ex alia, et quare plus optet hec quam infinita

(14) alia devotissima sacrarum scripturarum oblectamenta per doctores

(15) pertractari. Cum non videatur sufficere quod eum sequent(es) plus, ex

10) D. i. Matthias von Janov, obwohl die weiteren Angaben damit nicht in Einklang gebracht werden können.

11) Über eventuelle engere Kontakte ist nichts bekannt und auch kaum vorauszusetzen. Vgl.

V. Kybal, M. Matěj z Janova, Praha 1905, S. 223. Doch ist es bezeichnend für dieses Milieu.

12) Rom. 15,4.

13) Anspielung an 1. Cor. 7, 17 und ev. 12, 11 und Act. 4, 35.

n) Hierher gehört die vierzeilige Marginalie qui liber est Gorlici///eum accipe/re/ /debuit ?/ Mauricio 9 ).

o) Wohl im Sinne eines quibusdam.

p) Folgendes quod gestrichen.

9) $\mathrm{Da}$ das Papier zum Teil abgefallen ist, sind die fehlenden Worte nicht zu ermitteln. Item quod M im Grundtext gestrichen. Sollte wohl Anfang der nächsten Frage sein, vgl. folgende Zeile. 
(16) hoc disponanturq). Et cum multe sint consolaciones quas Deus propagat

(17) diligentibus se, respondit, quod reputet homines de necessitate salutis

(18) sufficienter esse informat(os), licet non omnes homines, qui indigent

(19) maxime doctrina, sicud ab ecclesia christianis simplicibus indultum

(20) est informari et informare et plus student(es) theologie et

(21) adhuc plus clericis studentibus theologiam precipue illa, que sunt in sacro

(22) canone contenta sicud materia Antichristi per quam non excluduntur alie

(23) consolaciones et scripture ad nostram doctrinam, ex quo omnia, que

(24) scripta sunt ${ }^{n}$ ) ad nostram doctrinam scripta sunt iuxta verba Apostoli12); eciam:

(25) sicud Deus d(ividi)t cuilibet secundum quod wlt et dividit quemadmodum wlt $^{13)}$

(26) sic /de iis?/, qui student materiam de Antichristo, aliqui magis (?) de

(27) ter(minis?) et aliqui de ac(cidentibus ?) cum circumstancia loci

(28) temporis, officiorum confertur /??/. Item interrogatus et rogatus quomodo dicat in

(29) scriptis /M(agistro)(?)/ suo oblatis, quod quilibet Christianus semper teneatur et sic de aliis, respondit,

(30) quod ibi hii sicud videlicet mem(oratus), sicud eo modo ita, quod sit sensus timendo (terminando ?)

(31) et insinuendo (??) eo modo, quo quilibet christianus et sic de aliis.

(32) (28) Item que tractanda sunt in scolis et in ecclesiis per predicatores de ista materia

(33) et quomodo sue opinioni de Antichristo deserviant, respondit, quod sua opinio sit

\section{Fragment B}

pag. ${ }^{\mathrm{r}}$ Margaretha Offe/n/grabe de Cometa/w/1)

(1) Item anno etc. die VIII mensis Junii predictis etc. se obtulit/Mar/

(2) garetha Offengrabe de Cometaw, virgo Pragensis diocesis, s/uspecta/

(3) de heresi, judicialiter citata accusata erat. Jurata igitur et interrogata, ubi

(4) nata sit, respondit, quod in Commetaw et quod pater suus vocabatur Nikel

(5) Grellenhart et mater Dorothea et quod non fuerunt de secta Waldensi

(6) et quod quidam Dressler in Commetaw ipsam primo induxit et quod

(7) dixerint sibi, quod eum sequi vellet, ostenderet sibi hominem, qui sibi peccata

12) Rom. 15,4.

13) Anspielung an 1. Cor. 7, 17 und ev. 12, 11 und Act. 4, 35.

q) Es folgt sechszeiliger marginaler hierher gehöriger Eintrag, aus dem nur super hoc///quod aug/// eo/// sint/// de///ad nobis(?) zu entziffern ist.

1) Komotau in Nordböhmen. 
(8) dimitteret et nichil mali doceret. Et ipsa consenciente ingressa ad

(9) heresiariam ad quandam cameram in domum predicti inductoris, cui primo

(10) confessa est, et quot bene sint VI anni. Et secundo in domo Petri Un-

(11) gari in Cadano ${ }^{2}$, eciam in quadam camera, quod in XLma proxima erat unus / annus/

(12) et quod tenuerit eos pro discipulis Domini, non presbyteris, et crediderit sibi per

(13) eos dimittere peccata melius /quam/ plebanus, quia missi a solo Deo et

(14) quod iniunxerint ei pro penitencia ad ieuniandum quartis et sextis feriis

(15) in aqua ${ }^{a}$ et pane et ad orandum omni die XXX Pater noster et

(16) festivis $L^{\text {ta }}$ et non Ave Maria. Et quod tenuerit penitenciam et crediderit

(17) ut supra, et penitenciam sibi proficere ad salutem. Et confessa interim presbyteris

(18) et susceperat Corpus Christi non dicendo se de secta, quia prohibita,

(19) et quod solum semel audiverit predicacionem eorum in domo Dressler

(20) predicti nullis presentibus, nisi tribus personis. /I/tem quod beatam Mariam

(21) et omnes sanctos ita diligentes non invocaverit sicut prius quia dixerint

(22) sibi et crediderit, non tamen plene, quod pro nobis possent orare. Item quod sic

(23) aliquem eciam intromiserit orare pro defunctis audiens et credens ad tempus,

(24) solum esse duas vias post hanc vitam et non purgatorium et sic eciam

(25) aliquam aquam benedicendam non proficere. Item omne juramentum crediderit esse

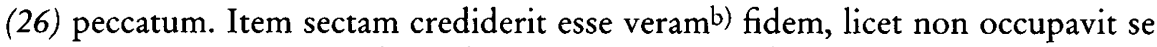

(27) an extra eam possit salvari aliquis. Et quod prius fuerit hic Prage coram

(28) inquisitore, propria voluntate jurata de dicenda veritate et recognoverit

(29) se confessam heresiariam et juraverit amplius nollec) facere et quod eam

(30) reinduxerit Anna uxor Ungari junioris et sic secundo et ultimo confessa

(31) fuerit heresiariam in domo Ungari ut supra et confessa fuerat eidem

(32) iuramenta, que fecerat coram inquisitore.

(33) Interrogata, an velit reverti ad unitatem fidei catholice et sancte matris Romane

(34) ecclesie, in ea vivere et mori et abiurare sectam Walden(sem) et eciam

(35) heresim, et se obligare ad penam relapsorum si relapsa fuerit et penitere

(36) publice et occulte et servare omnia et singula in iuramento abiuracionis

(37) sibi proposito, respondit ad omnia et singula quod sic, servatis omnibus et singulis

(38) et ad abiuracionem veteratoriis et sepissime superius assignatis .

2) Kaaden, kgl. Stadt in der Nähe von Komotau.

a) Marginal über eine Tilgung.

b) Wiederholtes veram getilgt.

c) Geschrieben deutlich als nonlle. 
(39) Acta sunt hec etc. presentibus Mathia de Wriczik publico notario3),

(40) Paulo de Meincz et Petro Herbordi clericis ${ }^{3}$ ) Wr/atislaviensis et/d)

(41) Augustensis diocesis et aliis multis.

pag. ${ }^{\vee}$ Margaretha Petri Sleyffer de Commetaw

(1) Anno etc., die etc. se obtulit Margaretha Petri Sleyffere)

(2) /de/f)Commetaw suspecta de heresi judicialiter citata et accusata.

(3) Vidua jurata igitur et interrogata ubi nata sit, respondit quod in Ewdlitz ${ }^{1)}$

(4) et quod pater suus vocabatur Wenczeslaus Krymaw et mater Crisana

(5) et quod non fuerant de secta Waldensi et quod ipsam induxerat Chunne

(6) Krewsynne defuncta in secta et sepulta in cimiterio in Comme-

(7) taw. Et quod dixerat sibi, quod si vellet audire bonam doctrinam, quod secum

(8) veniret et quod post hoc per ipsam predicacionem induceretur ad sectam ad do-

(9) mum Andres Dressler, ubi primo confessa sit heresiariorum quod et

(10) sint bene IX anni. Et quod quinquiesg) in vita suah) confessa

(11) sit et nominavit unum Nicolaum de Wienna, Nicolaum de

(12) Stiria et Nicolaum (!) et quod ultime confessa sit in domo Hicke

(13) Mulner ante Commetaw quod in XLma proxima fuerat unus annus.

(14) Et quod habuerit eos pro discipulis Domini, missis a Deo, sanctis, potentes (?)

(15) optime dimittere peccata. Item tamen presbiteros ordinatos ab episcopis, de quod

(16) iniuxerint sibi communiter pro penitencia quinquaginta Pater noster feriatis diebus et dominicis

(17) centum et non Ave Maria et ad ieiuniandum ieiunia alias consueta

(18) seu precepta aliis hominibus in pane et cervisia. Et quod tenetur /// /onem/

(19) pro posse et crediderit e/sse/ absolutam ac pinam proficere et de////tere.

(20) Item quod confessa non l(egitim)m(is) presbyteris et susceperit Corpus Christi non dicendo

(21) se de secta, nisi ante unum an/n/um, quia audiverat debere. Hoc

(22) esse occultum. Item quod bis forte audiverit predicaciones eorum. Item

(23) quod audiverit et crediderit tempore quo fuit in secta, beatam Mariam

(24) et sanctos in prima post gaudiisi) pro nobis non posse orare et quod

3) In dem mir bekannten Material (vgl.besonders oben die in Anm. 24 und 25 zit. Arbeiten) nicht nachweisbar.

4) Údlice in Nordböhmen in der Nähe von Komotau.

d) Papier abgerissen.

e) Geschrieben Fleyff//, da jedoch in der Überschrift deutlich das majuskle S vorkommt, ist diese zweite Nennung als Verschreibung zu bezeichnen.

f) Papier abgerissen.

g) Vorgehendes quiet getilgt.

h) Vorgehendes fuit getilgt.

i) Folgendes non getilgt. 
(25) reiuramen beate Marie et apostolis suis et celebraverit propter hoc,

(26) ut deus laudetur in sanctis suis. Item quod crediderit secundum infor-

(27) macionem heresiac(orum) solum esse infernum et celum et non pur-

(28) gatorium et ideo pro defunctis non oraverit et quod obtulerit in

(29) missis defunctorum solum propter Deum, non quod animas iuvaret. Item

(30) quod indulgencias, peregrinaciones et annum Jubileum non fecerit nisi

(31) propter Deum et crediderit faciendum, quia solum Deum credidit habere

(32) ius. Et si aliusk) quis ius haberet, se intromitteret et quod

(33) ymagines et reliquias sanctorum $\mathrm{l}$ ) venerata $\mathrm{si} / \mathrm{n} / \mathrm{t}$, solum

(34) propter Deum secundum doctrinam heresia(cam), non ad laudem sanctorum.

(35) Item omne juramentum in judicio qualitercumque factum, credidit esse peccatum.

(36) Item credidit solum Pater noster et Credo essent ${ }^{\mathrm{m}}$ ) orandum et eque bonum

(37) orandum in domo vel alibi sicut ${ }^{\text {n) }}$ in ecclesia. Item quod sectam

(38) suam crediderit esse veram fidem et extraneos dampnandos et

\section{Fragment C}

(1) /Wen/ceslaus de Czussan ${ }^{1)}$ confiteor et recognosco me graviter

(2) ... a fidei katholice unitate, de quod contrito corde doleo, abso-

(3) /lucionem et/penitenciam cum humilitate requiro. Insuper juro Deo omnipotenti

(4) /et sanctissimo/ in Christo patri et domino nostro, domino Bonifacio ${ }^{2)}$ pape nono et

(5) /venerabili in/ Christo patri et domino, domino Johanni archiepiscopo Pragensi $\left.{ }^{3}\right)$ et vobis

(6) /inquisitori?/nec non toti ac universali katholice Romane sancte matri ecclesie

(7) /quod iam/ nunquam communicabor cum hominibus secte Waldensium et cuiuscumque

(8) ... quocumque nomine valeat appellari, quamdiu me sciente tales

(9) ... heresiarchas et quoslibet eorum credentes hereticos fautores

(10) ... benefactores bona fide et sine dolo persequar pro posse meo

(11) ... ecclesie quanto potero fidelius et secrecius absque tamen mee in-

\footnotetext{
k) Verbessert aus alias.

l) Folgendes verballhorntes venel getilgt.

m) Nachträglich durch gleiche Hand über der Zeile.

n) Wiederholendes alib(i) getilgt.

1) Sušany, dt. Zuscha im Bezirk Komotau.

2) $1389-1404$.

3) Johann von Jenstein 1379-1396.
} 
(12) ... velabo et penitenciam, que mini propter predictam meam culpam iniungetur,

(13) /accepta/bo et complebo, tam publicam quam occultam, et si inantea, quod deus

(14) /absit/ lapsus fuero, penam relapsorum velud hereticus periurus et

(15) ... paciar et portabo. Preterea protestor et assero me puram

(16) /verita/tem de me et aliis, inquantum michi patuit, protulisse et

(17) ... constare poterit, me maliciose de veritate aliquid supprecisse vel tacuisse

(18) ... et absolucio obtente vel obtinende mini penitus nihil prosint

(19) ... hanc heresim et omnem aliam, quocunque nomine censeatur $a b$

(20) ... promitto, quod illibate de cetero servabo fidem, quam Romana

(21) /ecclesia/publice profitetur et predicat, sicut me deus adiuvet et

(22) /omnipotentis/ dei ewangelia et passio Jesu Christi gloriosa nunc et in mee mortis

(23) $/ \mathrm{AM} / \mathrm{EN}$ a).

(24) ... Andreas quondam Petri de Jawor, clericus Wratislaviensis

(25) /diocesis/ publicus imperiali auctoritate et universitatis juristarum studii

(26) /Pragensis/ iuratus notarius ${ }^{4}$ ), predictis arestacioni, incitacioni juramenti

(27) ... veritate prestacioni, deposicioni et abjuracioni omnibusque

(28) ... singulis premissis, dum sic, ut premittitur, fierent et per prefatum

(29) ... et coram eo fierent et agerentur, una cum prenominatis testibus

(30) /inter/fui eaque sic fieri vidi et audivi et ${ }^{\text {b) }}$ mea manu

(31) /scrip/si et hec subscripsi in fidem et evidens testimonium omnium premissorum.

(32) /Die/ XXVIc) mensis Augusti dominus inquisitor in stuba curie archiepiscopalis Pragensis

(33) ... enucciare consuevit, indulsit oretenus domino Ulrico dicto Cosar

(34) ... Czussensi, ut in die dominica proxime futura iniungat eis omnibus ... d)

(35) ... penitenciam publice post circuitum in facie ecclesie Wenceslao predicto, Hic ... d)

(36) Lender et Osanne (?) filii pie memorie Jekelico ... d)

(37) in presencia ... d)

4) Wohl Sohn des berühmten Beamten der Hofkanzlei Karls IV. und Wenzels IV. Vgl. hier oben in Anm. 25 und Josef Tř́šǩa, Životopisný slovník předhusitské pražské univerzity 1348-1409, Praha 1981, S. 28.

a) In größerer Schrift.

b) Folgendes in hanc gestrichen.

c) Wohl andere Hand und kleinere Schrift.

d) Das Blatt rechts unten am Schluß der vier letzten Zeilen zum Teil abgerissen. 